\title{
EFFECTS OF VOLATILE ANAESTHETIC AGENTS ON EEG ACTIVITY RECORDED IN LIMBIC AND SENSORY SYSTEMS
}

\author{
R.M. JUL.JEN, Ph.D., Eva M. Kavan, M.D., \& H.W. Eul.jotT, M.D., PH.D.
}

\section{INTHODUCTION}

MOST REPORTS on the effects of anaesthetic agents on the central nervous systems have been based on comprehensive studies of sensory pathways and the reticular activating system carried out on acute preparations. ${ }^{1-3}$ In these, the onset of analgesia cannot be determined because the animals are paralyzed and non-reflexic. Utilization of animals with electrodes chronically implanted in various brain centers circumvents this problem. In this latter model, electrodes are implanted under sterile technique, the animals allowed to recover and the actual investigations carried out several weeks later on an unrestrained animal, free of extraneous drug effects.

In the present study the central effects of two volatile anaesthetics frequently used in clinical anaesthesia (halothan and methoxyflurane) were compared with diethyl ether and with a new volatile agent, enflurane (Ethrane ${ }^{3}$ ).

\section{METHODS}

Under pentobarbital anaesthesia, eight cats $(3.0-4.8 \mathrm{~kg})$ were implanted with bipolar, concentric, stainless steel electrodes in the following nuclei using the coordinates of Snider and Niemer: ${ }^{0}$ nucleus ventralisposterolateralis $(A=9.5, L=$ $6.5, H=+2)$, nucleus centrum medianum $(A=7.5, L=3, H=+2)$, mesencephalic reticular formation $(A=2, L=2, H=0)$, nucleus amygdalae $(A=12$, $\overline{\mathrm{L}}=10, H=-7$ ), and pes hippocampi $(A=8, L=10, H=-6)$. In addition, bone screws were implanted over frontal, temporal, and/or pariental cortex.

Animals were permitted to recover from surgery for at least two weeks and control EEG tracings were then obtained. Another week was permitted to elapse before administration of the first anaesthetic, and further experiments were separated by at least one week. The sequence of drug administration was random. Each animal received each drug twice at intervals of at least five weeks.

Anaesthesia was administered to unpremedicated animals by a mask especially designed for cats, by means of an Ohio infant circle-absorber and an Ohio Anaesthetic Machine equipped with a copper kettle vaporizer. A total flow of 3 liters (2 liters air and 1 liter oxygen) per minute in a semi-closed system was used. End-tidal $\mathrm{CO}_{2}$ was monitored by a Beckman Infrared Gas Analyzer. Electrograph

-Department of Medical Pharmacology \& Therapeutics, University of Califomis, Irvine, California 92664 .

Supported by a grant from the Rebecea Payne Livingston Foundation and in part by Grant NS-09835, National Institutes of Neurological Diseases and Stroke.

Presented at the Annual Meeting, Canadian Anaesthetists' Society, June 30, 1971.

\section{3}

Canad. Anaesth. Soc. J., yol. 19, no. 3, May 1972 
activity of the various structures was recorded continuously on an 8 channel Grass Model 78 Polygraph.

Initially, each agent was administered in as high a concentration as the animals would tolerate without irritation to the upper respiratory system and the concentration was gradually increased in 2-3-minute intervals or longer until the animal lost reflex withdrawal following pinch of the hind paw. The minimum anaesthetic concentration required to achieve this areflexic state was maintained for at least 30 minutes. Anaesthetic was then discontinued and the animals observed until they regained consciousness.

Following completion of the series, the animals were sacrificed with pentobarbital, perfused with formalin, and electrode placement was verified histologically.

\section{Ether}

\section{Results}

Induction was started with 2.5 per cent ether in the gas mixture, and the concentration was gradually increased as tolerated until the animal did not respond to stimulation. The low voltage fast activity of the wakeful state continued in some leads in all animals during the first ten minutes of induction (Figure 1, 8

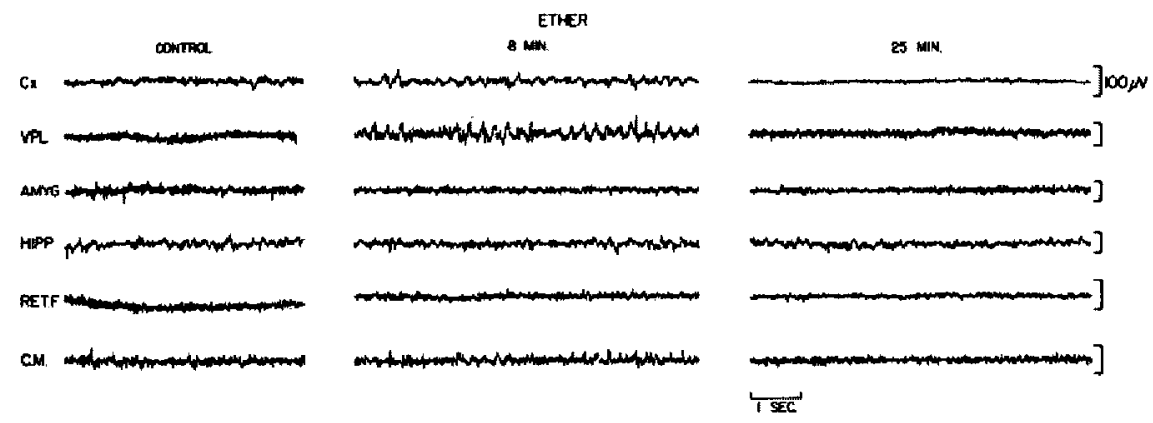

Figure 1. Effect of ether on the cortex $(\mathrm{Cx})$ and subcortical structures. See text for further explanation of this and the other figures.

minutes, 10 per cent). Some slowing with an increase in amplitude developed, being most prominent in cortex and nucleus ventralis posterolateralis (VPL). This pattern persisted for 10 to 15 minutes and gradually regressed to the appearance of the control tracings ( 25 minutes), although the concentration had to be further increased to 20 per cent and in some animals even to 25 per cent in order to achieve anaesthesia. The concentration of ether was then lowered to a level sufficient to prevent reflex withdrawal to pinch ( 15 per cent). No further changes were observed during the remainder of the experiment.

\section{Methoxyfurane}

Although the animals did not resist the administration of methoxyflurane, induction was slow. Considerable time (about 20 minutes) elapsed before concentrations of up to 1.7 per cent produced any change in the electrical activity of the brain (Figure 2). First alterations observed were increases in amplitude with 
CONTROA

METHOXYFLURANE

$C x$

VPL

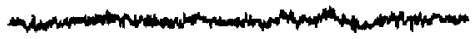

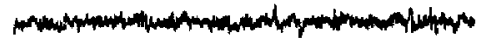

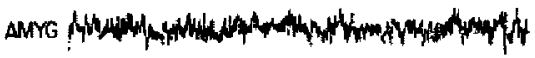

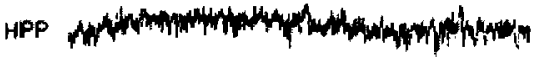

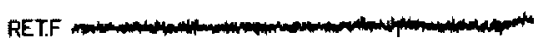

C.M

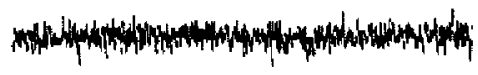

40 MaN.

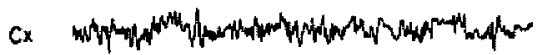

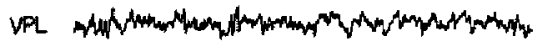

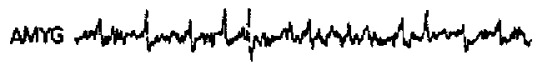

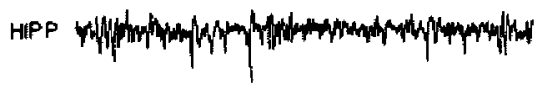

RET.F

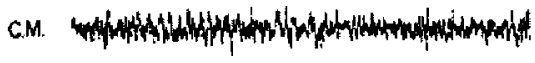

20 MiN

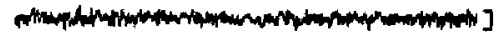

(n)

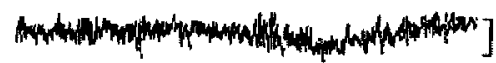

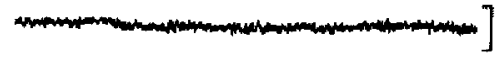

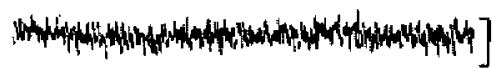

I SEC

\$5 MiN

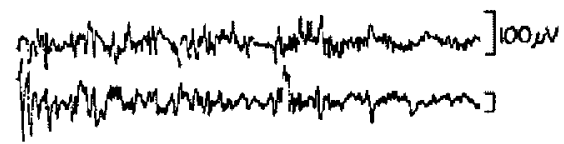

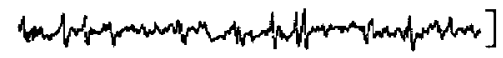

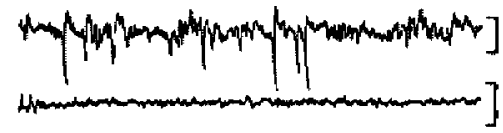

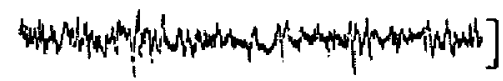

Ficune 2. Effect of methoxylurane on cortex $(\mathrm{Cx})$ and subcortical structures.

occasional spindles in cortex and hippocampus. Some slowing was observed in VPL and nucleus amygdalae. When the methoxyflurane concentration was increased to 3 per cent during the next 20 minutes (Figure 2, 40 minutes), there was further slowing in all structures with concomitant increases in voltage and occasional spikes particularly in structures of the limbic system. Delayed responses to pinch were observed. In the next 15 minutes, reflex withdrawal to pinch was lost and spike activity was recorded more frequently and more distinctly in sensory and limbic structures, with occasional short burst suppressions.

\section{Halothane}

A rapid induction ( 7 minutes or less) with 6 per cent halothane was obtained in all experiments. Most prominent alterations occurred early in nucleus amygdalae where 16-20 c.p.s. spindles were observed within one minute. We have described these changes in more detail elsewhere. ${ }^{7}$ At a maintenance concentration of approximately 4 per cent, considerable slowing and increases in voltage occurred in all structures except reticular formation (Figure 3, 18 minutes). Synchro- 


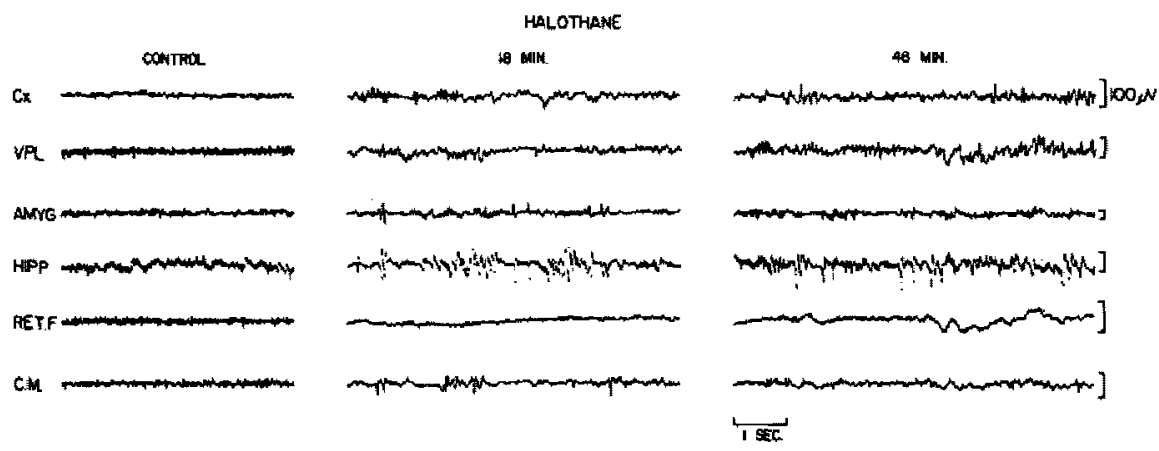

Ficure 3. Effect of halothane on cortex (Cx) and subcortical structures.

nization was recorded in cortex, nucleus amygdalae and to some extent in VPL. In the hippocampus, occasional spikes could be seen between periods of high voltage slow activity. During the next 30 minutes using the minimal concentration of halothane necessary to abolish reflex withdrawal, spiking continued in both sensory and limbic structures with superimposed fast activity.

\section{Enflurane}

Induction with 5 to 6 per cent enflurane was only slightly slower than with halothane. However, within 5 minutes (Figure 4), high voltage spike activity was
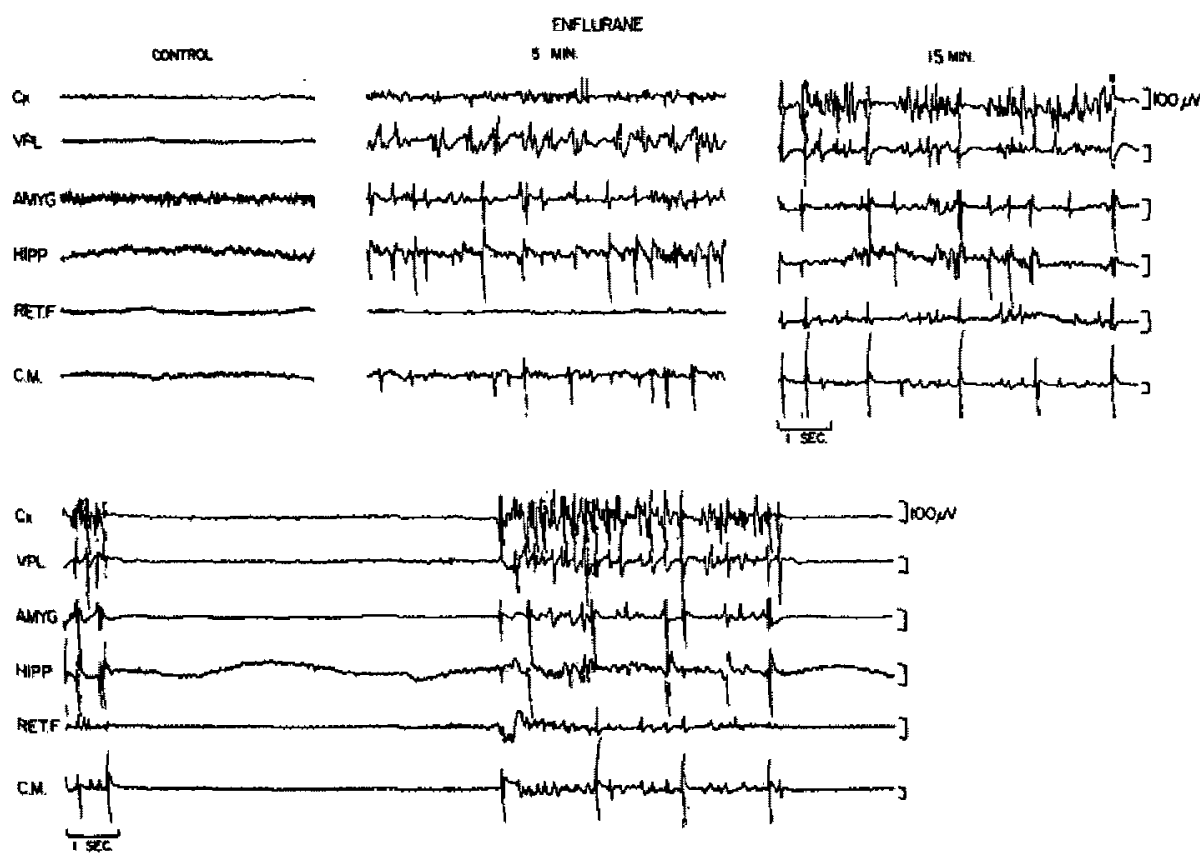

Ficure 4. Effect of enflurane on cortex $(\mathrm{Cx})$ and subcortical structures. Botton tracing was recorded at the minimal analgesia concentration. 
recorded in all structures except $\mathrm{RF}$ which appeared depressed. By 8 minutes reflex withdrawal to pinch was still present, spike activity became intense and short burst suppressions were observed. When reflexes were finally lost, continuous trains of spikes separated by prolonged periods of depression in all leads were recorded (Figure 4, bottom tracings). If the concentration was decreased, burst suppressions became shorter but reflex withdrawal to pinch reappeared (Figure 4, 15 minutes).

\section{COMMENTS}

In the present study, vapor concentrations of all agents were considerably higher than those employed in humans, but within the range recommended for animal surgery. ${ }^{8}$ No animal received any drug other than the one under investigation.

We observed neither respiratory depression as measured by end-tidal $\mathrm{CO}_{2}$ concentrations nor cardiac arrhythmias. Blood pressure was not determined because it is extremely difficult to monitor in cats by a conservative method; the apparatus used in the first experiments proved unsatisfactory and improvements in monitoring this parameter are being investigated.

The electrophysiological changes induced during induction following administration of volatile anaesthetics have been described elsewhere. ${ }^{7}$ In the present study, we wished to determine whether bioelectrical phenomena observed during induction continued during maintenance when lower concentrations are administered. It is well known that most anaesthesic agents depress respiration. We have therefore avoided deeper levels of anaesthesia to eliminate electrographic effects which may result from hypoxia and $\mathrm{CO}_{2}$ retention.

Ether is known to produce analgesia in stage one of anaesthesia. Thus, the minimal changes which we observed in the EEG were not unexpected. Since we deliberately did not deepen anaesthesia beyond the level used clinically, we have not observed the epileptiform activity reported by Mori et al., at deeper levels of anaesthesia. ${ }^{8}$

With methoxyflurane, onset of analgesia was much slower than with ether and was accompanied by high voltage spike activity in nucleus amygdalae, VPL, and occasionally in cortex.

With the other halogenated agents (halothane and enflurane), induction was rapid and vapor concentrations of both agents in the gas mixture for induction and maintenance differed only slightly. The electrographic responses to both agents, however, differed markedly. With both agents, initial electrographic alterations occurred in the limbic system. Halothane was characterized by 16-20 c.p.s. oscillations in nucleus amygdalae and occasional hippocampal spikes. Continued administration resulted in few additional alterations. With enflurane, onset of spike activity was rapid and not limited to the structures of the limbic system. Continued administration of enflurane resulted in appearance of trains of high voltage spike activity separated by prolonged periods of total electrical silence.

Thus, the present results indicate that administration of fluorinated volatile anaesthetios is accompanied by varying degrees of electrographic correlates of epileptiform activity. Halothane induced the least epileptoid activity while en- 
flurane induced the most, often mimicking the central effects of gamma-hydroxybutyrate (GHB) , ${ }^{10}$ although the GHB-induced hypersynchronous high frequency generalized seizures were not observed at minimal anaesthetic concentrations of enflurane. The electrographic effects of deeper levels of enflurane anaesthesia are, at present, not known.

In the human subject, cortical epileptoid activity similar to that reported herein has been noted. Bart, et al.,11 demonstrated high voltage spike activity and burst suppressions with electrical silence at surgical levels of enflurane. The electrical activity was accompanied by symmetrical abnormal motor activity in 2 of their 4 patients. Similarly, Virtue, et al., ${ }^{12}$ reported burst suppressions with motor involvement in both dogs and humans. Lebowitz, et al, ${ }^{13}$ were unable to correlate muscular twitchings with the spike activity observed in the EEG of their patients.

Thus, we feel that electrographic epileptoid activity is a likely counterpart to enflurane administration and should be considered in the future evaluation of the compound's usefulness as a clinical anaesthetic. Other new anaesthetic agents should also be examined for central electrographic effects during evaluation as a potential addition to the armamentarium of the anaesthetist.

\section{SUMMARY}

As part of a systematic study of the effects of anaesthetic agents on cortical and subcortical activity of experimental animals, diethyl ether, halothane, methoxyflurane, and enflurane (Ethrane) were administered to cats with chronicallyimplanted electrodes sterotaxically placed in selected nuclei of the sensory system (centrum medianum, ventralis posterior lateralus, and mesencephalic reticular formation) and in representative areas of the limbic system (pes hipoccampi and nucleus amygdalae). Skull electrodes were placed over frontal, parietal and/or temporal cortex.

Following induction, an anaesthetic state was maintained for at least $30 \mathrm{~min}$ utes and deeper levels of anaesthesia were avoided. Minimal electrographic changes were observed with ether. Spiking, particularly on the limbic system, was observed with the 3 halogenated compounds. These changes were most pronounced with enflurane.

We would like to thank Mr. J.F. Vitcha of Ohio Medical Products for providing the enflurane ( $\bar{E}$ thrane $)$ used in these experiments.

\section{RÉsUḾ̃}

Au cours d'une étude systématique sur les effets d'agents anesthésiques sur l'activité corticale et sous"corticale d'animaux de laboratoire, on a administré de l'éther de l'halothane, du méthoxyflurane et de l'Ethrane à des chats porteurs d'électrodes installées à demeure et implantées de façon stéréotaxique dans les noyaux choisis du système sensoriel et dans des zones représentant le système limbique. Des électrodes craniennes étaient placées sur le cortex frontal, pariétal et/ou temporal.

Après l'induction, on maintenait l'anesthésie durant au moins 30 minutes en 
évitant une anesthésie profonde. L'éther produisait des changements électrographiques minimes. Les trois composés halogénés ont déclenché l'apparition d'ondes, surtout sur le système limbique. Ces changements ont été surtout prononcés avec l'Ethrane.

Ainsi, nous avons limpression que l'activité épileptoïde électrographique est comme une contre-partie de l'administration de l'Ethrane et qu'il faut en tenir compte dans l'évaluation future de l'utilité de ce produit comme anesthésique clinique. D'autres nouveaux agents anesthésiques devraient aussi être examinés quant à leurs effets électrographiques centraux durant leur évaluation comme addition possible à l'arsenal anesthésique.

\section{REFERENCES}

1. Fonpes, A. \& Monzson, B.R. Cortical response to sensory stimulation under deep barbiturate narcosis. J. Neurophysiol. 2: 112-128 (1939).

2. Monuzzi, G. \& MAcoun, H.W. Brain stem reticular formation and activation of the EEC. Electroencephalog. \& Clin. Neurophysiol. 1: 455 473 (1949).

3. Rande, D.T. Colsins, W.F, DAvis, H.S., \& Dilon, W.H. Differential susceptibility of afferent pathways to anesthetic agents in cats. Am. J. Physiol. 192; 305-310 (1958).

4. Denavit, $M$. Action différentielle de quelques anesthésiques sur les réponses dè structures alimentées par les voies spécifiques on associatives. Anesth. Analg. Réanim. 20: $747-809$ (1963).

5. Jenkins, L.C., Lanc, G.M., Fouluks, J.G., \& Pennose, G.S. Experimental central nervous system studies related to anaesthesia: Clinical implications. I, Anesthesia and the brain stem reticular formation. II. Effect of reduced sensory inflow on anaesthetic requirements. Can. Anaesth. Soc. J. 10: 634-647 (1963).

6. SNmEn, A.S., \& NIEMre, W.T. A stereotaxic atlas of the cat brain. U. of Chicago Press (1961).

7. KAvaN, E.M., JuLIEN, R.M., \& LUCERo, J. Differential effect of volatile anesthetic agents on limbic and sensory systems. Submitted for publication.

8. Cumford, D.H, \& Soma, L.R, Feline anesthesia. Fed. Proc. 28: 1479-1499 (1969).

9. Mort, $\mathbb{K}_{\text {, MItan, }}$ H., \& Fujrta, M. Epileptogenic properties of diethyl ether on the cat central nervous system. Flectroencephalog. \& Clin. Neurophysiol. 30: 345-349 (1971).

10. Winters, W.D., MORI, K, SPOONER, C.E., BAver, R.O. The neurophysiology of anesthesia. Anesthesiology 28: 65-79 (1967).

1I. BArt, A.J., HOMT, J., \& LnNDE, H.W. Changes in power spectra of electroencephalograms duing anesthesia with fluroene, methoxyfurane and Ethrane. Anesth. \& Analg. 50: 5363(1971).

12. Virtere, R.W., Lund, L.O., Phelps, M., Voced, J., BeckwitT, H., \& Heron, M. Difluoromethyl 1,1,2-trifluoro-2-chloroethyl ether as an anaesthetic agent: Results with dogs, and a preliminary note on observations with man. Can. Anaesth. Soc. J. 13: 233-241 (1966).

13. Lkegowniz, M.H., Burr, C.S., \& Dinoon, J.B. Clinical investigation of compound 347 (Ethrane). Anesth. \& Analg, 49: 1-10 (1970). 